\title{
El hombre y los valores humanos en el Concilio Vaticano II
}

Leyendo atentamente las Constituciones, los Decretos y las Declaraciones del Concilio, nos percatamos de que suenan en cada una de sus páginas los valores humanos y de que el tema-hombre se ha convertido en preocupación. Es difícil hallar otro punto que se haya tratado con mayor amplitud y es fácilmente comprensible que así fuera. Si se trataba de renovación, de caridad, de diálogo, de servicio, de unidad y de fraternidad, era natural que se presentara como primer problema el enganche para la humanidad y se colocara al hombre y sus valores, como centro de convergencia de todos los participantes del ser racional. Se han oído quejas también en diferentes círculos sobre este hecho, pensando en un humanismo excesivo de la Iglesia actual, pero ya Pablo VI lo ha desenmascarado también. Adolecía esta visión de una perspectiva clara en la interpretación.

Colocados en el ángulo de los Padres conciliares, podemos subrayar que el Concilio se ba preocupado del hombre tah cual es y que además tiene conciencia de esta preocupación, nacida de la caridad cristiana: "En efecto, la caridad cristiana se extiende a todos sin distinción de raza, de condición social o de religión; no espera lucro o agradecimiento algunos, pues como Dios nos amó con amor gratuito, así los fieles han de vivir preocupados por el hombre mismo, amándolo con el mismo sentimiento con que Dios lo buscó. Pues como Cristo recorría las ciudades y las aldeas curando todos los males y enfermedades en prueba de la llegada del reino de Dios (cf. Mt. 9, 35 ss.; Act. 10, 38), así la Iglesia se une por medio de sus hijos a los hombres de cualquier condición; pero especialmente con los pobres y los afligidos y a ellos se consagra gozosa (cf. 2 Cor. 12, 15). Participa en sus gozos y en sus dolores, conoce los anhelos y los enigmas de la vida y sufre con ellos en las angustias de la muerte. A los que buscan la paz desea responderles en diálogo fraterno ofreciéndoles la paz y la luz que brotan del Evangelio" ${ }^{1}$. Y ya en el primer Mensaje de los Padres a todos los hombres confesa-

1 Decr. Ad gentes = Sobre la actividad misionera de la Iglesia 12 (Concilio 
ban con la gallardía y la humildad de quien se siente bajo una tarea inmensa y se sensibiliza con los demás: "Reunidos de todas las naciones que alumbra el sol, llevamos en nuestras corazones las ansias de todos los pueblos confiados a nosotros, las angustias del cuerpo y del alma, los sufrimientos, los deseos, las esperanzas. Ponemos insistentemente nuestro corazón sobre todas las angustias que hoy afligen a los hombres. Ante todo debe volar nuestra alma hacia los más humildes, los más pobres, los más débiles e, imitando a Cristo, hemos de compadecernos de las turbas oprimidas por el hambre, por la miseria, por la ignorancia, puestos constantemente nuestros ojos sobre quienes, por falta de los medios necesarios, no han alcanzado todavía una condición de vida digna del hombre" 2 .

Diríamos que se ha hecho responsable de la humanidad presente, que ama a la humanidad de hoy: "No se ha apartado nuestra preocupación de las condiciones del tiempo presente, ni se ha atenuado nuestro amor a la humanidad que nos rodea" 3 . En el Concilio "hemos aprendido - dirá también el Papaa conocer mejor a la Humanidad en sus complejos y formidables problemas y a amarla más en orden a su bienestar, a su paz y a su salvación" "4. Si pretendía conocer las condiciones actuales del mundo y del hombre que vive en él, no era solamente para complacerse y decirse que también ella se daba cuenta de los problemas, sino para amar a esta humanidad, preocuparse por ella y propinarle las soluciones necesarias para una mejora en todos los órdenes. Las palabras del amor suenan fuertes ahora: "El Concilio of rece a la Iglesia, a nosotros especialmente, la visión panorámica del mundo. ¿Podrá la Iglesia, podremos nosotros hacer otra cosa que mirarlo y amarlo? (cf. Mc. 10, 21): Esta contemplación será uno de los hechos principales de la incipiente sesión de nuestro Concilio: ahora y, sobre todo, amor; amor a los hombres de hoy, como son y donde están, a todos. Mientras otras corrientes de pensamiento y de acción proclaman principios bien diversos para construir la civilización de los hombres, como la potencia, la riqueza, la ciencia, la lucha, el interés u otras cosas, la Iglesia proclama el amor. El Concilio es un acto solemne de amor a la Humanidad. Cristo nos asista para que así sea de verdad" 5 .

Sin embargo un dolor ensombrecía el corazón del Papa y ensombrece el corazón de la Iglesia entera. El amor puede ser rechazado, el amor puede ser abofeteado y la Iglesia tiene que seguir el camino de Cristo, dejar que el amor sufra

Vaticano II. Constituciones. Decretos. Declaraciones. Madrid, ed. BAC, 1965; 583-584). Citaremos sencillamente con la sigla BAC, seguida de la página correspondiente.

2 Mensaje de los Padres del Concilio, BAiC, 5.

3 PABLo VI, Al. 4-XII-1963, BAC, 777.

4 ID., Al. 18-XI-1965, BAC, 808.

5 ID., Al. 10-IX-1965, BAC, 802 . 
en silencio, que el dolor se cebe en el amor. Es el choque de sentimientos, el drama de la existencia cristiana que no ignora que ante su mensaje se adoptan muy diferentes actitudes: "Y en este punto - continuaba Pablo VI- nos asalta un pensamiento que parece contrastar esta suave y fuerte irradiación de nuestra cristiana y humana simpatía hacia toda persona, hacia todo pueblo de esta tierra. Sabemos efectivamente, por amarga y siempre actual experiencia, que también el amor, y quizá especialmente el amor, encuentra y provoca indiferencia, oposición, desprecio, hostilidad. Ningún drama, ninguna tragedia fue semejante al sacrificio de Cristo, quien precisamente por su amor y por la enemistad de los otros padeció la cruz. El arte de amar se cambia con frecuencia en arte de sufrir. Así, la Iglesia, ¿ podrá desistir de su compromiso de amor por los riesgos y dificultades que se le opongan?" 6 . No, no desistirá de amar. Amará la misma oposición y enemistad, amará al hombre con sus dolores y sus angustias, sus dramas y sus tragedias, sus sonrisas y sus lágrimas, y procurará en una caridad efectiva prestarle una ayuda que no humilla.

Porque el amor la guía y porque esa es la concepción de su humanismo y la solución al problema humano, por eso puede presentarse en la Constitución pastoral Gaudium et spes sobre la Iglesia en el mundo actual con estas intensivas palabras: "Los gozos y las esperanzas, las tristezas y las angustias de los hombres de nuestro tiempo, sobre todo de los pobres y de cuantos sufren, son a la vez gozos y esperanzas, tristezas y angustias de los discípulos de Cristo. Nada hay verdaderamente humano que no encuentre eco en su corazón. La comunidad cristiana está integrada por hombres que, reunidos en Cristo, son guiados por el Espíritu Santo en su peregrinar hacia el reino del Padre, y han recibido la buena nueva de salvación para comunicarla a todos. La Iglesia, por ello, se siente íntima y realmente solidaria del género humano y de su historia" 7. De ello se habían hecho particioneros desde el principio ${ }^{8}$.

$\mathrm{Si}$, por razones de orden teológico y habida cuenta del doble que constituye la Iglesia, su humanismo tiene que dejarse sentir cada día en grado mayor, hoy como nunca resultaría esto, cuando el hombre se ha trocado en cima y centro de todo interés. En todos los órdenes de la existencia el primer plano lo obtiene siempre el hombre y la Iglesia no quedaba fuera de esta corriente 9 . No obstante, se nos recuerda algo más: los participantes al Concilio son también hombres, con una sensibilidad y una problemática vivida a la altura de los tiempos y con un conocimiento de lo neurálgico auscultado desde el gabinete presidencial. Es admirable contemplar a Pablo VI extasiarse ante la asamblea de hombres reunidos

6 Ibid.

7 Const. past. Gaudium et spes = Sobre la Iglesia en el mundo actual 1 , BAC, 209-210.

8 Mensaje de los Padres del Concilio, BAC, 5-7.

9 Const. past. Gaudium ert spess 12, B.AC, 223-224. 
en Concilio, e introspeccionar esas intimidades que palpitan al unísono. Son hombres: quizá alguien lo hubiera olvidado y por eso a la hora de criticar algunas cosas ocurridas careció de comprensión suficiente. "He aquí una asamblea de hombres libres como ninguno de intereses propios y vanos, y comprometidos como ninguno en el testimonio de las verdades divinas; hombres, y por tanto débiles y falaces, pero convencidos de poder pronunciar verdades que no admiten contestación ni término; hombres, hijos de nuestro tiempo y de nuestra tierra, pero erigidos sobre el tiempo y sobre la tierra para asumir sobre nuestras espaldas el peso de nuestros hermanos y conducirlos a la salvación espiritual, con una entrega total, con un amor mayor que el corazón que lo alberga, con una tensión que podría aparecer temeraria, que está llena de serena confianza, en buscar el sentido de la vida humana y de la historia para darles valor, grandeza, belleza y unidad en Cristo; sólo en Cristo nuestro Señor. Es estupendo, hermanos que àquí estáis; es estupendo, hombres que desde fuera nos observáis. ¿Podremos ver alguna vez escena más grande, más piadosa, más dramática y más solemne?" 10 .

$Y$ estos hombres, como los demás, quizá con visión y solución distinta a lo humano, trágico y siempre angustioso, se han preocupado de la humanidad, la han amado. Esta era la cifra de todo el Concilio y de quienes han representado en él al pueblo católico. Pero ¿qué bumanidad y qué bombre ban tenido ante sus ojos $y$ ban sentido con gravedad y hondura? No ciertamente a un hombre y a una humanidad abstracta e insensible, no al hombre visto por la inteligencia especulativa, sino que ya en su lenguaje demostraban su ansia pastoral, su anhelo de acercamiento al "hombre de carne y hueso, que se siente ser aquí y ahora" (Unamuno). "No se ha dirigido sólo a la inteligencia especulativa, sino que ha procurado expresarse también con el estilo de la conversación corriente de hoy, a la cual el recurso a la experiencia vivida y el empleo del sentimiento cordial confieren una vivacidad más atractiva y una mayor fuerza persuasiva; ha hablado al hombre de hoy tal cual es" ${ }^{11}$. Y colocados sobre esta vía han emprendido un minucioso análisis de ese hombre, vulgar y corriente, que desarrolla su actividad en medio de tirones contrarios, en vertical y en horizontal.

\section{¿QUÉ HOMBRE HA PREOCUPADO AL CONCILIO?}

En tiempos precedentes se había acomodado el pensamiento eclesiástico a la concepción del hombre en vigor, $y$ hoy ha intentado también esta adaptación a la nueva perspectiva humana que se abría. No le ha preocupado el hombre teórico, la unión sustancial entre el alma y el cuerpo - cosa ya adquirida y por 
tanto conservada-, sino el hombre problemático, o para expresarlo con palabras de Pablo VI, en su profundidad actual, se ha puesto en presencia "del hombre vivo, del hombre enteramente ocupado de sí, del hombre que no sólo se hace el centro de todo su interés, sino que se atreve a llamarse principio y razón de toda realidad. Todo el hombre fenoménico, es decir, cubierto con las vestiduras de sus innumerables apariencias, se ha levantado ante la asamblea de los padres conciliares, también ellos hombres, todos pastores y hermanos, y, por tanto, atentos y amorosos; se ha levantado el hombre trágico en sus propios dramas, el hombre superhombre de ayer y de hoy, y, por lo mismo, frágil y falso, egoísta y feroz; luego, el hombre descontento de sí, que ríe y que llora; el hombre versátil, siempre dispuesto a declamar cualquier papel, y el hombre rígido, que cultiva solamente la realidad científica; el hombre tal cual es, que piensa, que ama, que trabaja, que está siempre a la expectativa de algo, el filius accrescens (Gen. 49, 22); el hombre sagrado por la inocencia de su infancia, por el misterio de su pobreza, por la piedad de su dolor; el hombre individualista y el hombre social; el hombre "laudator temporis acti" (que alaba los tiempos pasados) y el hombre que sueña en el porvenir; el hombre pecador y el hombre santo..." ${ }^{12}$. He aquí el hombre que interesaba al Concilio, diríamos que es el hombre existencial - no le llamemos existencialista-, no el hombre abstracto sin raigambre en la cuotidianidad. Ante él se ha detenido y a él pretende elevarlo y liberarlo.

Ese hombre dramático ostenta su doble faz, como la humanidad que constituye su conjunto y que ha aparecido también al Concilio. $Y$ éste no ha cerrado los ojos a su realidad. La humanidad no existe, pero existen y viven y se contorsionan los hombres que la constituyen y éstos se hacían angustia y postulaban una solución. "¿Y qué ha visto este augusto Sínodo en la humanidad, que se ha puesto a estudiarla a la luz de la divinidad? Ha considerado, una vez más, su eterna doble fisonomía: la miseria y la grandeza del hombre, su mal profundo, innegable e incurable por sí mismo, y su bien, que sobrevive, siempre marcado de arcana belleza y de invicta soberanía" ${ }^{13}$. Ese doble crea el drama del hombre, drama que Pablo VI, en la clausura solemne del Concilio; abordaba exponiendo el saludo final con las esperanzas de renovación que proyectaba el Sínodo ecuménico. "Nuestro saludo - decía- se hâce así ideal. ¿Se hace sueño? ¿Se hace poesía? ¿Se hace hipérbole, convencional y vacía, como sucede frecuentemente en nuestras habituales efusiones de felicitación? No. Se hace ideal, pero no un ideal irreal. Fijad todavía un instante la atención en lo que voy a decir. Cuando nosotros, los hombres, empujamos núestros pensamientos y nuestros deseos hacia una concèpción ideal de la vida, nos encontramos inmediataménte o en la

12 ID., ibid., BAC, 816.

13 ID., ibid., BAC, 817 . 
utopía, o en la caricatura retórica, o en la ilusión, o en la desilusión. El hombre conserva la aspiración inextinguible hacia la perfección ideal y total, pero no llega por sí a alcanzarla, ni conceptualmente ni mucho menos con la experiencia y la realidad. Lo sabemos: éste es el drama del hombre, del rey destronado" ${ }^{14}$. Ponemos límite a nuestro comentario. Hablan las palabras por sí solas. El drama humano se resuelve en su doble, en su miseria y en su grandeza, en esas aspiraciones inagotables por algo absoluto y en la imposibilidad natural para conseguirlo. A esto ha querido responder justamente el Concilio, recogiendo las pulsaciones del corazón humano que palpita hoy más velozmente en busca de la felicidad, de la paz, del amor.

Sin embargo, el Concilio podría haber admitido ante estos hechos una doble actitud: pesimista y deprimente $u$ optimista y exultante. La doble vertiente en que la vida del hombre se desenvuelve da margen para ambas. ¿En cuál de ellas se ha situado el Concilio? Con la firme esperanza de la salvación y con la profunda fe en Cristo y en su misión redentora, no se ha detenido en el pesimismo, sino que ba encarado la realidad bumana con ojos claros y límpidos, con mirada amorosa y simpatizante. Ya Juan XXIII, desde el inicio, se había alzado contra los profetas del desastre y de lo catastrófico. Suenan a dolor sus palabras y a experiencia amarga: "En el cotidiano ejercicio de nuestro ministerio pastoral llegan, a veces, a nuestros oídos, hiriéndolos, ciertas insinuaciones de almas que, aunque con celo ardiente, carecen del sentido de la discreción y de la medida. Tales son quieres en los tiempos modernos no ven otra cosa que prevaricación y ruina. Van diciendo que nuestra hora, en comparación con las pasadas, ha empeorado, y así se comportan como quienes nada tienen que aprender de la Historia, la cual sigue siendo maestra de la vida, y como si en los tiempos de los precedentes Concilios ecuménicos todo procediese próspera y rectamente en torno a la doctrina y a la moral cristiana, así como en torno a la justa libertad de la Iglesia.

"Mas Nos parece necesario decir que disentimos de esos profetas de calamidades que siempre están anunciando infaustos sucesos como si fuese inminente el fin de los tiempos. En el presente orden de cosas, en el cual parece apreciarse un nuevo orden de relaciones humanas, es preciso reconocer los arcanos designios de la Providencia divina, que a través de los acontecimientos y de las mismas obras de los hombres, muchas veces sin que ellos lo esperen, se llevan a término, haciendo que todo, incluso las fragilidades humanas, redunden en bien para la Iglesia" 15.

El optimismo y el providencialismo del Papa bueno superaba a todos los profetas de la calamidad y a todos los trenos jeremíacos. En esta línea proseguiría

14 ID., Al. 8-XII-1965, BAC', 822.

15 JUAN XXIII, Al. 11-X-1962, BAC, 747. 
la visión conciliar y esa misma permitiría a Pablo VI enfrentar ese hombre descrito con Dios y apreciar los resultados del confronte con ojos de simpatía y de optimismo. "El humanismo laico y profano ha aparecido, finalmente, en toda su terrible estatura $y$, en cierto sentido, ha desafiado al Concilio. La religión del Dios que se ha hecho hombre, se ha encontrado con la religión - porque tal es del hombre que se hace Dios. ¿Qué ha sucedido? ¿Un choque, una lucha, una condenación? Podía haberse dado, pero no se produjo. La antigua historia del samaritano ha sido la pauta de la espiritualidad del Concilio. Una simpatía inmensa lo ha penetrado todo. El descubrimiento de las necesidades humanas -y son tanto mayores cuanto más grande se hace el hijo de la tierra- ha absorbido la atención de nuestro Sínodo. Vosotros, humanistas modernos, que renunciáis a la trascendencia de las cosas supremas, conferidle siquiera este mérito y reconoced. nuestro nuevo humanismo: también nosotros $-\mathrm{y}$ más que nadiesomos promotores del hombre" ${ }^{16}$. Simpatía y amor han invadido todos los campos de lo humano y ya los Padres comenzaron por sentir con la humanidad doliente y hacerse cargo de sus múltiples angustias y dolores, a la vez que de su progreso y de su técnica. No ha temido el humanismo profano, lo ha escuchado, porque quiere reconocer en él sus valores y redimirlos plenamente con la confianza en lo superior y en el Superior. Por eso, examinada la bifronte fisonomía de la humanidad, confiesa nuevamente esta verdad del optimismo, no irenista a secas - porque también ve la parte negativa-: "Pero hace falta reconocer que este Concilio se ha detenido más en el aspecto dichoso del hombre que en el desdichado. Su postura ha sido muy a conciencia optimista. Una corriente de afecto y de admiración se ha volcado del Concilio hacia el mundo moderno. Ha reprobado los errores, sí, porque lo exige no menos la caridad que la verdad; pero, para las personas, sólo invitación, respeto y amor. El Concilio ha enviado al mundo contemporáneo, en lugar de deprimentes diagnósticos, remedios alentadores; en vez de funestos presagios, mensajes de esperanza; sus valores no sólo han sido respetados, sino honrados, sostenidos sus incesantes esfuerzos, sus aspiraciones, purificadas y bendecidas" ${ }^{17}$.

A este respecto trae a la recordación muchas de las concesiones y de los reconocimientos que se han hecho en el Concilio. Prácticamente la línea pastoral que es amor y esperanza, fundadas en una fe honda, se manifiesta en este sentido humano. Se quiere atraer no por la condenación del mundo, sino por la confranza y el amor, por el testimonio y la presencia. Entre esos valores respetados se nos citan: "las innumerables lenguas de los pueblos hoy existentes han sido admitidas para expresar litúrgicamente la palabra de los hombres a Dios y la Palabra de Dios a los hombres; al hombre en cuanto tal se le ha teconocido su

16 PABLo VI, Al. 7-XII-1965, BAIC, 816.

17 ID., ibid., BAC, 817. 
vocación fundamental a una plenitud de derechos y a una trascendencia de destinos; sus supremas aspiraciones a la existencia, a la dignidad de la persona; a la honrada libertad, a la cultura, a la renovación del orden social, a la justicia, a la paz, han sido purificadas y estimuladas; y a todos los hombres se les ha dirigido la invitación pastoral y misional a la luz evangélica" ${ }^{18}$.

Por desconocer o no penetrar en lo íntimo de esta realidad conciliar se han emitido juicios, excesivamente ligeros y superficiales, sobre el Concilio en to tocante a estos puntos. Surgían, como siempre, las corrientes: aquellos que pensaban que, por fin, la Iglesia abandonaba su maniqueismo y su platonismo - esa especie de desprecio por los valores humanos-, que se encaminaba por la vía de un sano pelagianismo o de un naturalismo de buena leva; y aquellos, por el contrario, que lo tachaban de una ignorancia, sino real, al menos aparente de la gracia y de todo el orden sobrenatural. La verdad, como siempre también, estaba en medio de dos visiones extremas. Hay un optimismo radical, una simpatía por los valores y los logros del espíritu humano, pero hay también - tendremos ocasión de examinarlo- un análisis de los desequilibrios del mundo, debidos a los desequilibrios del hombre, procedentes éstos del pecado. Y si la historia del samaritano ha sido el paradigma de la espiritualidad del Concilio, esto quiere decir sencillamente que a ese hombre había que auparlo de su postración, gra* tuitamente, pagarle el coste de su curación y ofrecerle todos los remedios y los cuidados que necesitara. $Y$ esto además sin que él lo exija, sino por amor y caridad, porque se le ama. No se trataba de un reconocimiento pueril y superficial, sino de una mirada profunda de la realidad humana, descarnadamente examinada y diagnosticada en la esperanza de hacer valer todavía aquello que puede vivificarla desde el interior. Gritar a los males del hombre no es ponerles remedio, en cambio alentar en lo bueno y aceptarlo es entusiasmar para mayores realizaciones de bondad.

\section{¿QUÉ ES EL HOMBRE?}

El Concilio ha dedicado su atención al hombre y ha respondido a sus graves interrogantes a la luz de la revelación y de la fe. Son muchas las cuestiones que hoy se plantea angustiosamente el hombre, tales como: "¿Qué es el hombre? ¿Cuál es el sentido del dolor, del mal, de la muerte, que, a pesar de tantos progresos hechos, subsisten todavía? ¿Qué valor tienen las victorias logradas a tan caro precio? ¿Qué puede dar el hombre a la sociedad? ¿Qué puede esperar de ella? ¿Qué hay después de esta vida temporal?" 19. Y ante estos interrogantes

18 Ibid.

19 Const. past. Gaudium et spes 10, BAC, 221. 
se hace otros el Concilio en la Constitución pastoral sobre la Iglesia en el mundo actual, que insinúa en estos términos: "¿Qué piensa del hombre la Iglesia? ¿Qué criterios fundamentales deben recomendarse para levantar el edificio de la sociedad actual? ¿Qué sentido último tiene la acción humana en el universo? $\mathrm{He}$ aquí las preguntas que aguardan respuesta" ${ }^{20}$. Como amaba al hombre, como se preocupaba por él, tenía que enfrentar su problema y a ello se apresta decidido, como ofreciendo la solución, la única solución válida para sacar al hombre de sus angustiosas encrucijadas.

¿Qué nos dice, pues, el Concilio sobre el hombre? Inicia el estudio del hombre constatando un hecho común a creyentes y a no creyentes, en el que concuerdan, y es que todos los bienes de la tierra deben ordenarse en función del hombre, centro y cima de todos ellos". Y siendo el hombre el centro de todas las cosas terrenas y a su vez la cima y la cúspide de las mismas, ¿qué es ese hombre? Las respuestas han sido muy diversas y variadas y a veces hasta contradictorias, "exaltándose el hombre a sí mismo como regla absoluta o bundiéndose basta la desesperación". Ante ello el sagrado Concilio, alezcionado por la revelación, ofrece una respuesta que "perfile la verdadera situación del hombre, dé explicación a sus enfermedades y puedan conocerse simultáneamente y con acierto la dignidad y la vocación propias del hombre". Dado el doble tirón que siente el hombre, ese rey destronado, era necesario buscarle una solución y responderle para calmar su inquietud y darle una salida. Entonces el primer punto que el Concilio considera es el hombre, becho a imagen de Dios. "La Biblia nos enseña que el hombre ha sido creado "a imagen de Dios", con capacidad para conocer y amar a su Creador, y que por Dios ha sido constituído señor de la entera creación visible para gobernarla y usarla glorificando a Dios". Un primer punto, por consiguiente, quedaba asegurado de este modo: su grandísima y altísima dignidad -imagen de Dios-. Pero además añade también aquí el otro hecho fundamental del hombre que es su socialidad: "Pero Dios no creó al hombre en solitario. Desde el principio los bizo hombre y mujer (Gen. 1, 27). Esta sociedad de hombre y mujer es la expresión primera de la comunión de personas humanas. El hombre es, en efecto, por su íntima naturaleza, un ser social y no puede vivir ni desplegar sus cualidades sin relacionarse con los demás. Dios, pues, nos dice también la Biblia, miró cuanto babía becho y lo juzgó muy bueno (Gen. 1, 31)" 21.

Esta primera consideración del hombre, plenamente bíblica, como bíblica quería ser la respuesta de los padres conciliares a los interrogantes del hombre, nos manifiesta estos tres hechos fundamentales: la dignidad de la persona bumana, becha a imagen de Dios y constituida por $E l$ señor de la creación visible, la socialidad y la bondad. Y queremos seguir en este sentido optimista, aunque el Conci-

20 Ibid. 11, BAC, 223.

21 Ibid. 12, BAC, 223-225. 
lio trata inmediatamente del pecado. Nos permitimos dejar este aspecto para luego. Ahora seguimos el hilo del discurso y continuamos en nuestra interrogación sobre el hombre y su constitución. Porque Dios miró cuanto había hecho y juzgó que era muy bueno, el hombre fue juzgado tal como salía de las manos de Dios bueno y muy bueno. ¿En qué radicaba y consistía esa bondad? A ello nos contesta por pasos también el Concilio y pisaremos sus huellas.

El bombre es una unidad en cuerpo y alma, una totalidad corporal y anímica: "En la unidad de un cuerpo y un alma, el hombre, por su misma condición corporal, es una síntesis del universo material, el cual alcanza por medio del hombre su más alta cima y alza la voz para la libre alabanza del Creador" ${ }^{22}$. Siendo el cuerpo parte integrante del hombre, no debe despreciarlo, sino que "debe tenerlo por bueno, honrándolo como criatura de Dios, que ha de resucitar el último día". El cuerpo pertenece al hombre y es en cierta medida el hombre, de tal suerte que no hay hombre sin cuerpo, aunque el cuerpo no sea el hombre. No es, sin embargo, un instrumento más del hombre. No sólo tiene el cuerpo, sino que es su cuerpo también. No nos interesa, empero, entrar ahora a examinar estas relaciones personales del cuerpo, sino revelar las enseñanzas del Concilio sobre el mismo.

Pero si ya en el cuerfo el hombre se demuestra como cima del universo material y por él canta la creación la alabanza al Creador, "afirmando así el hombre su superioridad sobre el universo material y considerándose no ya como partícula de la naturaleza o como elemento anónimo de la ciudad humana", aparecen por su alma otros valores que le elevan al máximo. La interioridad le constituye superior al universo entero: " $y$ a esas profundidades retorna cuando entra dentro de su corazón, donde Dios le aguarda, escrutador de los corazones, y donde él personalmente bajo la mirada de Dios, decide su propio destino". Esto lo conduce a dos puntos capitales en lo anímico, y es al descubrimiento, a través de la interioridad, de la espiritualidad y de la inmortalidad del hombre, "no siendo entonces juguete de un espejismo ilusorio provocado solamente por las condiciones físicas y sociales exteriores, sino que toca, por el contrario, la verdad más profunda de la realidad" ${ }^{23}$. El cuerfo le colocaba ante la corruptibilidad y la muerte ${ }^{24}$, la interioridad le descubre ese flanco suferior que le estimula y le inquieta, le aumenta el ansia de la inmortalidad.

La interioridad, sin embargo, no se desarrolla vacíamente, sino que presenta valores que aquí se ponen de relieve. En primer lugar se alude a la'inteligencia, que hace al hombre superior a todo otro ser terreno, participa de la luż divina y a través de ella progresan las ciencias y las técnicas. No obstante, ésta misma debe perfeccionarse con la sabiduría, "que atrae con suavidad la mente del hombre " a la búsqueda y al amor de la verdad y del bien. Imbuído por ella, el hombre' 
se alza por medio de lo visible hacia lo invisible". "Tiene razón el hombre, participante de la luz de la inteligencia divina, cuando afirma que por virtud de su inteligencia es superior al universo material" 25 . La riqueza de esta interioridad no se agota con la inteligencia, sino que en ella y por ella brilla otra luz que es la conciencia. Entrando en la intimidad, el hombre "en lo más profundo de su conciencia descubre la existencia de una ley que él no se dicta a sí mismo, pero a la cual debe obedecer y, cuya voz resuena, cuando es necesario, en los oídos de su corazón, advirtiéndole que debe amar y practicar el bien y que debe evitar el mal: haz esto, evita aquello. Porque el hombre tiene una ley escrita por Dios en su corazón, en cuya obediencia consiste la dignidad humana y por la cual será juzgado personalmente. La conciencia es el núcleo más secreto y el sagrario del hombre, en el que éste se siente a solas con Dios, cuya voz resuena en el recinto más íntimo de aquella. Es la conciencia la que de modo admirable da a conocer esa ley, cuyo cumplimiento consiste en el amor de Dios y del prójimo (cf. Mt. 22, 37-40; Gal. 5, 14)" 26. "La fidelidad a esta conciencia une a los cristianos a los demás hombres para buscar la verdad y resolver con acierto los numerosos problemas morales que se presentan al individuo y a la sociedad" 27. Esta comunión interior que crean los individuos entre sí para un fin - búsqueda de la verdad y solución de problemas morales- y por consiguiente, comunión social y activa, es un bien de primera calidad que precisa un relieve especial. Una primera unidad vendría de la participación de la luz divina por todos, y esta segunda, de la fidelidad a la misma, impresa y escrita en la propia conciencia individual con fines sociales.

La orientación hacia la verdad y hacia el bien, para la búsqueda y la solución de los problemas que aquejan al hombre, procede radicalmente de una especie de instinto racional, pero debe brotar del uso de la libertad. "La orientación del hombre hacia el bien - dice el Concilio- sólo se logra con el uso de la libertad, la cual posee un valor que nuestros contemporáneos ensalzán con entusiasmo. Y con toda razón... La verdadera libertad es signo eminente de la imagen divina en el hombre. Dios ha querido "dejar al hombre en manos de su propia decisión" (cfr. Eccli. 15, 14), para que así busque espontáneamente a su Creador, y, adhiriéndose libremente a éste' alcance la plena y bienaventurada perfección" 28. Signo eminente de la imagen divina en el hombre pero lo es la verdadera libertad. Su valor no puede ponerse en tela de juicio, si bien es cierto que el hecho de que las decisiones queden en manos del hombre, infunde el temblor del riesgo limitativo de toda decisión y, por tanto, reduce a la persona a la medida y pru-

24 Ibid. 18, BAC, 230.

Ibid. 15, BAC, 227.

Ibid. 16, BAC, 228.

Ibid. BAIC, 228-229.

8 Ibid. 17, BAC, 229. 
dencia, al cálculo y no ya sólo a la espontaneidad. Dios ha creído mucho más digno dejar que el hombre libremente se decida por su cuenta a dirigirse al bien y a la verdad, como ser racional y libre, y esta grandeza integra los valores del hombre, elevándolos a un grado increible, casi divino.

Este sentido optimista en la consideración del hombre el Concilio lo ha expresado en los términos que hemos visto. No obstante, no ha olvidado el segundo plano, aunque no lo releve tanto. Había comenzado por explicitar los cambios del mundo en todos los órdenes, social, psicológico, moral, religioso; había también mostrado sus temores y esperanzas ante el mundo, y sobre todo revelado los grandes desequilibrios existentes también en él ${ }^{29}$, y las aspiraciones más universales de la humanidad ${ }^{30}$. El hombre es actor y protagonista en esta tragedia del mundo y de la humanidad actual. Si existen desequilibrios en el mundo, éstos tienen una relación directa con los desequilibrios internos del hombre y en última instancia son estos desequilibrios los que crean los problemas mundanos y sociales. "En hecho de verdad, los desequilibrios que fatigan al mundo moderno están conectados con ese otro desequilibrio fundamental que hunde sus raíces en el corazón humano. Son muchos los elementos que se combaten en el propio interior del hombre. A fuer de creatura, el hombre experimenta múltiples limitaciones; se siente, sin embargo, ilimitado en sus deseos y llamado a una vida superior. Atraído por muchas solicitaciones, tiene que elegir y que renunciar. Más aún, como enfermo y pecador, no raramente hace lo que no quiere y deja de hacer lo que querría llevar a cabo (cfr. Rom. 7, 14 y ss.). Por ello siente en sí mismo la división, que tantas y tan graves discordias provoca en la sociedad. Son muchísimos los que, tarados en su vida por el materialismo práctico, no quieren saber nada de la clara percepción de este dramático estado, o bien, oprimidos por la miseria, no tienen tiempo para ponerse a considerarlo. Muchos piensan hallar su descanso en una interpretación de la realidad propuesta de múltiples maneras. Otros esperan del solo esfuerzo humano la verdadera y plena liberación de la humanidad y abrigan el convencimiento de que el futuro reino del hombre sobre la tierra saciará plenamente todos sus deseos. Y no faltan, por otra parte, quienes, desesperando de poder dar a la vida un sentido exacto, alaban la insolencia de quienes piensan que la existencia carece de toda significación propia y se esfuerzan por darle un sentido puramente subjetivo" ${ }^{31}$. El origen de estos desequilibrios generales en el hombre nos lo propondrá de nuevo, hablando de la guerra ${ }^{32}$.

Con la revelación, el Concilio ha buscado la causa de este dissequilibrio interno del hombre y la ha saludado en el pecado, ya que Dios había creado al hom-

29. Ibid. 8, BAC, 217-218.

30 Ibid. 9, BA.C, 218-220.

31 Ibid. 10, BAC, 220-221.

32 Ibid. 78-79, BAC, 334-336. 
bre en justicia y lo había hecho bueno, juzgándolo también El así al finalizar su obra. La revelación hablaba de pecado y con ello explicaba ese doble en el hombre, pero además se recuerda que esa explicación está conforme con la misma experiencia interior. Las palabras del Concilio nos dan la clave de la explicación: "Creado por Dios en la justicia, el hombre, sin embargo, por instigación del demonio, en el propio exordio de la historia, abusó de su libertad, levantándose contra Dios y pretendiendo alcanzar su propio fin al margen de Dios. Conocieron a Dios, pero no le glorificaron como a Dios. Oscurecieron su estúpido corazón y prefirieron servir a la criatura, no al Creador (cfr. Rom. 1, 21-25). Lo que la revelación divina nos dice coircide con la experiencia. El hombre, en efecto, cuando examina su corazón, comprueba su inclinación al mal y se siente anegado por muchos males, que no pueden tener origen en su Santo Creador. Al negarse con frecuencia a reconocer a Dios como su principio, rompe el hombre la debida subordinación a su fin último y también toda su ordenación, tanto por lo que toca a su propia persona como a las relaciones con los demás y con el resto de la creación.

"Es esto lo que explica la división íntima del hombre. Toda la vida humana, la individual y la colectiva, se presenta como lucha, y por cierto dramática, entre el bien y el mal, entre la luz y las tinieblas. Más todavía, el hombre se nota incapaz de domeñar con eficacia por sí solo los ataques del mal, hasta el punto de sentirse como aherrojado entre cadenas. Pero el Señor vino en persona para liberar y vigorizar al hombre, renovándole interiormente y expulsando al príncipe de este mundo (Io. 12, 31), que le retenía en la esclavitud del pecado (cfr. Io. 8, 34). El pecado merma al hombre, impidiéndole lograr su propia plenítud" 33 .

"A la luz de esta revelación, pues, la sublime vocación y la miseria profunda que el hombre experimenta hallan simultáneamente su última explicación" 34 . El pecado, en consecuencia, nos explicaría la tendencia del hombre hacia el mal y esa división íntima que le duele como algo inherente a su propia vida humana. No es, sin embargo, un dolor de algo concreto, es algo que le sigue en toda su constitución y en su misma actividad, de suerte que aquellos valores que optimísticamente hemos visto como la parte positiva del hombre, tienen siempre una contrapartida, procedente de este segundo elemento que se inserta en la estructura humana. De este modo nos hallamos que si es necesario por una parte honrar y venerar el cuerpo y los valores corporales, es preciso conservar un orden fijado por Dios también para ellos, porque el hombre "herido por el pecado, experimenta la rebelión del cuerpo. La propia dignidad humana pide, pues, que glorifique a Dios en su cuerpo (cfr. I Cor. 6, 13-20) y no permita que lo escla-

33. Ibid. 13, BAC, 225-226.

34 Ibid. 
vicen las inclinaciones depravadas de su corazón" ${ }^{35}$. El cuerpo que representaba un valor, expone al riesgo de la caída y de la entrega a sus placeres. La dignidad humana impone dominar sus tendencias hacia el mal, originadas del pecado.

Esas depravadas inclinaciones que pueden esclavizar el cuerpo pertenecen al corazón y a la inteligencia, diríamos a la intimidad. "La inteligencia no se ciñe solamente a los fenómenos. Tiene capacidad para alcanzar la realidad inteligible con verdadera certeza, aunque a consecuencia del pecado esté parcialmente oscurecida y debilitada" ${ }^{36}$. Lo mismo sucede con la conciencia que ha de guiar al hombre en su obrar moral, que pierde a veces su dignidad "despreocupándose de buscar la verdad y el bien y yendo progresivamente entenebreciéndose por el hábito del pecado" 37. La libertad, se ve en muchos momentos esclavizada por las pasiones y "con frecuencia es fomentada de forma depravada como si fuese pura licencia para hacer cualquier cosa, con tal que deleite, aunque sea mala" 38. También ella ha sufrido la herida del pecado y arrastra en sus decisiones la inclinación hacia la comodidad y el placer, hacia lo fácil y placentero.

Si en lo personal el pecado reina con alguna frecuencia, ese régimen se traslada también a lo social, y las divisiones entre los hombres, las reyertas y las luchas nacen de la misma fuente. Porque además la actividad humana se oprime y degrada también bajo la presión del pecado. "La Sagrada Escritura, con quien está de acuerdo la experiencia de los siglos, enseña a la familia humana que el progreso, altamente beneficioso para el hombre, también encierra, sin embargo, gran tentación; pues los individuos y las colectividades, subvertida la jerarquía de los valores y mezclado el bien con el mal, no miran más que a lo suyo, olvidando lo ajeno. Lo que hace que el mundo no sea ya ámbito de una auténtica fraternidad, mientras el poder acrecido de la humanidad está amenazado con destruir al propio género humano" 39 .

Este doble en el hombre imfone una seria reflexión. Los valores humanos no se pierden, aunque el pecado los aminore y los empobrezca. Continúan fundamentalmente en el hombre, a veces bajo las cenizas de una perversión conducida a conciencia de la malicia. Y empeña a la búsqueda de una solución. Las decisiones humanas para resolver el problema han resultado vanas o ineficaces y hacen tomar conciencia al hombre de su impotencia en la lucha por salvar todos los valores auténticos, más aún le exigen una mirada superior. La Iglesia, consciente de todos estos hechos, sensible a las dificultades y a las angustias, intenta en Concilio su solución, en conformidad con la revelación y la fe y la balla en Cristo, hombre perfecto, en quien se da cita el más pleno humanismo y en quien

35 Ibid. 14, BAC, 226.

Ibid. 15, BAC, 227 .

Ibid. 16, BAC, 229.

Ibid. 17, BAC, 229 .

Ibid. 37, BAC, 257-258. 
los valores aparecen en su pureza sublime ${ }^{40}$. Fija en Cristo y con la conciencia de su vigor, se apresta a salvar y a liberar al hombre. "Es la persona del hombre la que hay que salvar. Es la sociedad humana la que hay que renovar. Es, por consiguiente, el hombre, pero el hombre todo entero, cuerpo y alma, corazón y conciencia, inteligencia y voluntad, quien centrará las explicaciones que van a seguir" 41. Inicia esta tarea por aceptar y fomentar los valores humanos, y los recibe para librarlos de su caducidad, como se decía en el Mensaje a los gobernantes ${ }^{42}$. Admite la bondad de esos valores, considera sus desviaciones y augura una purificación necesaria: "Estos valores, por proceder de la inteligencia que Dios ha dado al hombre, poseen una bondad extraordinaria, pero, a causa de la corrupción del corazón humano, sufren con frecuencia desviaciones contrarias a su debida ordenación. Por ello necesitan purificación" 43.

La purificación comenzará por el hombre, dado que a su desequilibrio y a su división interior se deben las desviaciones contrarias a la ordenación exigida por el Creador. Pero el hombre está en continua actividad, desarrolla una lucha en dos frentes, o mejor en un solo frente con divisiones contrarias, una pelea entre el bien y el mal, y debe luchar para que el bien venza al mal. La correspondencia y la colaboración a la gracia que será el arma poderosa en la batalla ha de manifestarla en la pelea constante por no dejarse arrastrar de lo instintivo y por hacer brillar lo sublime que le invita y le incita. Le toca establecer la unidad en sí mismo para constituir luego la unidad en el universo y en la sociedad. "A través de toda la historia humana existe una dura batalla contra el poder de las tinieblas, que, iniciada en los orígenes del mundo, durará, como dice el Señor, hasta el día final (cfr. Mt. 24, 13; 13, 24-30 y 36-43). Enzarzado en esta pelea, el hombre ha de luchar continuamente para acatar el bien, y sólo a costa de grandes esfuerzos, con la ayuda de la gracia de Dios, es capaz de establecer la unidad en' sí mismo" "44. Mas para darse un sentido a su lucha, "ha de tener ante los ojos la cruz, la resurrección de Cristo a través de las cuales se ha purificado lo humano de su soberbia y egoísmo".

Y examinando el otro aspecto del ser humano, su aspecto social, para huir a la ética individualista y conservar el equilibrio entre los dos elementos, sociedad y persona ${ }^{45}$, recuerda la semejanza y la imagen de Dios en el hombre, prosiguiendo: "Esta semejanza demuestra que el hombre, úníca criatura terrestre a la que Dios ha amado por sí misma, no puede encontrar su propia plenitud si no es en

\footnotetext{
40. Tendremos ocasión de ver a Cristo, como solución a los problemas humanos, en el capítulo siguiente. Arquí solamente hacemos la referencia a El para seguir el curso de nuestra exposición.

41 Const. past. Gaudium et spes 3, BAC, 211.

42 Mensaje a los gobernantes, BAC, 732 .

43 Const. past. Gaudium et spes 11, BAC, 223.

44 Ibid. 37, BAC, 258.

45 Ibid. 30, BAC, 248-249.
} 
la entrega sincera de sí mismo a los demás (cfr. Lc. 17, 33)" 46. De esta suerte el hombre quedaba plenamente definido no para la inteligencia especulativa solamente, sino para el lenguaje corriente. Hallaba su plenitud en la entrega a los demás, en una entrega sincera y generosa de sí mismo, que necesitaba en precedencia el equilibrio y la unidad interior para no crear hacia fuera divisiones, como fruto de la propia íntima división.

El hombre quedaba constituído de este modo en una doble perspectiva, en su dimensión estática, común para todos, en la unidad de un cuerpo y un alma con cuanto esto lleva consigo, y en su dimensión dinámica, en su actividad interior, siempre en vaivén entre las múltiples tendencias que experimenta en sí mismo, y en sus relaciones con el mundo y con las personas. El Concilio no ha querido conscientemente insistir en los aspectos negativos de lo humano, no olvidando, sin embargo, el origen de todo ello y apelando decisivamente en cuanto examina al pecado como raíz tanto de las divisiones personales como de las luchas sociales y de los desequilibrios. Como esos valores están sometidos y en pugna continua con el riesgo de degradación, esboza y desflora una superación y una liberación de los valores positivos a través de Cristo, que dará sentido y significado a todo lo humano. Al presente, empero, nos interesa seguir el curso de lo humano y por eso nos preguntamos ahora.

\section{¿Cú́les son los valores humanos?}

Es capital la respuesta a este interrogante, porque de él dependerá la educación y formación que exige a los valores humanos y la salvación de los mismós en lo personal y lo social. No será difícil, por otra parte, desprenderlos, supuesto que en el análisis que ha hecho del hombre, los ha ido estudiando y deslindando con claridad más en su aspecto positivo que en el negativo.

Diríamos que el valor que resuena en casi todas las páginas de los documentos promulgados en el Concilio es la dignidad de la persona bimana. Esta, empero, sería la suma total de los valores y en ella convergerían todos, reducidos a èsa expresión que aparece subrayada para cada uno de los problemas. Si se nos habla de continuo de buscar una vida más humana y de procurarla por todos los medios, ésta dependerá de la dignidad humana. Sin embargo, es preciso destilar la dignidad humana de sus fuentes y así podremos considerar como su primer fundamento el ser becho a imagen de Dios, como hemos ya señalado, citando la doctrina conciliar, que refería la bíblica. $Y$ por tanto por ser criatura de Dios a su imagen era digna de veneración y de honor. Se saludaba la "creciente conciencia

46 Ibid. 24, BAC, 241. 
de la dignidad de la persona humana excelsa", como un gran signo de nuestro tiempo ${ }^{47}$. Lo había ya hecho la Pacem in terris sobre todo, a la que se recurre en la Const. past. Sobre la Iglesia en el mundo actual con muchísima frecuencia, y ella reforzaba los principios que se habían dado en la Mater et Magistra, también abundantemente citada.

El origen común y el fin para todos iguala a los hombres entre sí y les confiere el derecho a esa dignidad. "La igualdad fundamental entre todos los hombres exige un reconocimiento cada vez mayor. Porque todos ellos, dotados de alma racional y creados a imagen de Dios, tienen la misma naturaleza y el mismo origen. $Y$ porque, redimidos por Cristo, disfrutan de la misma vocación y de idéntico destino" 48 . Lo mismo se acrecentaba en los pueblos, en el ansia de revelar aquello que es común para todos, con el fin de hallar el punto de enganche para una relación con las religiones no cristianas 49 . Toda su dignidad, además de ese origen, se abre al "estar dotados de razón y de voluntad libre" ${ }^{50}$. Los demás elementos han quedado enaltecidos, al hablar del hombre.

Esta dignidad trae consigo el respeto a la persona bumana, no ya como una mera coexistencia, sino como una exigencia del amor. Es una conclusión práctica de "la máxima urgencia, que el Concilio inculca, de forma que cada uno, sin excepción de nadie, debe considerar al prójimo como "otro yo", cuidando en primer lugar de su vida y de los medios necesarios para vivirla dignamente, no sea que imitemos a aquel rico que se despreocupó totalmente del pobre Lázaro (cfr. Lc. 16, 18-31" 51. Y esto ha de llevarse también al amor de los enemigos y de los adversarios $\mathbf{5 2}$.

Tanto supone este respeto a la persona que no le está permitido a la sociedad misma atentar contra él, de suerte que persona y sociedad se condicionan mutuamente, sabiendo además que dada la indole social del hombre, ésta no es, para él, una sobrecarga accidental ${ }^{53}$. Y es, por tanto, un valor nuevo, que avala la dignidad de la persona la libertad. No insistimos en él. En la Decl. Sobre la libertad religiosa se proyecta como primer tema la dignidad de la persona humana para extraer inmediata conclusión en la libertad y el derecho a la misma. Recordamos estas palabras, al expresar el fundamento de la libertad religiosa: "Este Concilio Vaticano declará que la persona humana tiene derecho a la libertad religiosa... Declara, además, que el derecho a la libertad religiosa está realmente fundado en la dignidad misma de la persona humana, tal como se la cono-

47 Ibid. 26, BAC, 243.

48 Ibid. 29, BAC, 247.

49 Decl. Sobre las relaciones de la Iglesia con las religiones no cristianas 1 , BAC, 722-723.

50 Decl. Dignitatis humanae = Sobre la libertad religiosa 2, BAC, 682.

51 Const. past. Gaudium et spes 27, BAC, 245.

52 Ibid. 28, BAC, 246.

53. Ibid. 25, BAC, 242. 
ce por la palabra revelada y por la misma razón natural" ${ }^{54}$. Los demás puntos no serán más que una secuencia de este primer principio.

Sin embargo, los valores humanos no quedaban reducidos a esto a través de las enseñanzas del Concilio. De la dignidad de la persona humana derivan, en efecto, todos, pero se explicitan, aunque no mucho, sí al menos en algunos pasajes. De hecho estos valores humanos, sobre todo sociales, se apreciaban ya "en la reciprocidad de servicios, $y$ en el diálogo con los hermanos" 55 . Y a ellos se alude en el Decr. Sobre el apostolado de los seglares: "Para cultivar las relaciones humanas es necesario que se acrecienten los valores verdaderamente humanos, sobre todo el arte de la convivencia fraterna, de la cooperación y del diálogo" ${ }^{56}$. He aquí valores, que como veremos, tienen un máximo exponente en nuestro mundo y se insertan en el complejo de la totalidad personal. A ellos se exigirá luego la formación, sea de los seglares, sea también $-\mathrm{y}$ si se quiere como una urgencia superior- de los sacerdotes y religiosos.

A la convivencia fraterna, la cooperación y el diálogo debe unirse un recto juicio crítico ${ }^{57}$, como manifiestan también diferentes lugares de los documentos, de modo especial aquellas relaciones con la libertad y la dignidad de la persona humana ${ }^{58}$. De esta suerte se completaba la persona en todos sus elementos. $Y$ podía concluirse sobre la formasión de los séglares al apostolado, cosa extensible a todos los demás: "En la satisfacción de todas las exigencias de la formación hay que tener siempre presente la unidad y la integridad de la persona humana de forma que quede a salvo y se acreciente su armonía y su equilibrio" ${ }^{59}$. El valor supremo, siempre a la vista, se concretaría en la armonía, unidad y equilibrio de la persona bumana.

\section{DIGNIDAD DE LA PERSONA HUMANA Y RESPETO.}

La aplicación del respeto a los valores humanos se hace urgente en todos los documentos y se exhorta de los modos más variados a ella. Porque "la actividad humana individual y colectiva o el conjunto ingente de esfuerzos realizados por el hombre a lo largo de los siglos para lograr mejores condiciones de vida, considerado en sí mismo, responde a la voluntad de Dios" ${ }^{60}$. Y entonces "cuanto más se acreciente el poder del hombre, más amplia es su responsabilidad indivi-

54 Decl. Dignitates humanaie 12, BAC', 681.

55 Const. past. Gaudium et spes 25, BAC, 242.

56 Decr. Sobre el apostolado de los seglares 29, BAC, 542.

57 Ibid.

58 Decl. Dignitatis humanae 3, BAC, 683; Decr. Sobre la formación sacer- " dotal 11, BAC, 466.

59 Decr. Sobre el apostollado de los seglares 29, BAC, 542-543.

60 Const. past. Gaudium et spes 34, BAC, 254. 
dual y colectiva" ${ }^{61}$. Ante la responsabilidad que impone toda actividad y toda acción, surge inmediata la ordenación "auténtica de la misma. Esta ordenación, como hemos recordado ya, tiene por fin y cima al hombre: "así como procede del hombre, así también se ordena al hombre. Pues éste, con su acción, no sólo transforma las cosas y la sociedad, sino que se perfecciona a sí mismo. Aprende mucho, cultiva sus facultades, se supera y se trasciende. Tal superación, rectamente entendida, es más importante que las riquezas exteriores que puedan acumularse. El hombre vale más por lo que es que por lo que tiene. Asimismo, cuanto llevan a cabo los hombres para lograr más justicia, mayor fraternidad y un más humano planteamiento en los problemas sociales, vale más que los progresos técnicos. Pues dichos progresos pueden of recer, como si dijéramos, el material para la promoción humana, pero por sí solos no pueden llevarla a cabo.

"Por tanto, ésta es la norma de la actividad humana: que; de acuerdo con los designios y voluntad divinos, sea conforme al auténtico bien del género humano y permita al hombre como individuo y como miembro de la sociedad, cultivar y realizar íntegramente su plena vocación" 62

A través del hombre se ordena todo a Dios y lo creado se ordena al hombre. Siendo esto verdad, aparece ya claro cómo toda actividad humana debe ir sellada por el respeto a la persona y a su dignidad. En cada uno de los órdenes será preciso aplicar la norma que acaba de darnos el Concilio para la actividad, en la que se mira a la voluntad divina para conformarse al bien del género humano y al cultivo de la persona. Entonces no resultarían ya vanas y sin base las aplicaciones a los diferentes aspectos de la vida social. El Concilio lo ha realizado y de ello desprendemos nosotros lo más importante, porque en realidad podemos afirmar, como lo hemos ya dicho y lo repetimos, que la dignidad de la persona humana suena en casi todos los documentos promulgados.

En lo religioso se nos presenta como primer fruto de la dignidad de la persona la libertad. Esta halla su fundamento en aquella y por tanto se declara como un derecho de la persona, que exige un respeto ${ }^{63}$. Esa libertad se requiere sobre tódo para los bienes del espíritu, y por tanto, si la persona humana está obligada a buscar la verdad y a abrazarla, máxime en lo tocante a Dios y a su Iglësia ${ }^{64}$, necesita libertad para ello, dada sú vinculación a Dios, y hacerlo con medios adecuados ${ }^{65}$. Porque esa libertad no sólo la postula la dignidad de la persona, sino su vinculación a Dios y la libertad del acto de fe. Y tiene "sus raíces en la divina

61 Ibid., BAC, 255

62 Ibid. 35, BAC, 255-256.

63 Cfr. toda la Decl. Sobre la libertadi religiosa, pero sobre todó 1-2, BAC, 679-682, que inicia precisamente Dignitatis humanae personae?

64 Ibid. 1, BAC, 680 .

65. Ibid. 3, BAC, 683 . 
revelación" ${ }^{66}$. La Iglesia, por su parte, "fiel a la verdad evangélica, sigue el camino de Cristo y de los apóstoles cuando reconoce y promueve la libertad religiosa como conforme a la dignidad humana y a la revelación de Dios" ${ }^{67}$. La libertad religiosa bunde, pues, sus raices en la dignidad bumana.

No obstante el campo de aplicaciones se amplía también aquí. Ya no se trata solamente de la libertad religiosa en general, sino que ese principio se aplica en cierta medida a todos los sectores de la vida eclesiástica. En la obediencia se pide responsabilidad y libertad y amplitud para los presbíteros, por ejemplo ${ }^{68}$, sin olvidar, claro está, la disposición de ánimo para acatar el juicio de quienes desempeñan la función principal en el régimen de la Iglesia de Dios. A éstos, empero, se les recordará el respeto a la personalidad del súbdito y sobre todo su espiritu de servicio, como estudiaremos.

De esa libertad responsable y de ese respeto a la persona se habla con mayor claridad en el Decr. Perfectae caritatis para los religiosos. Adelantando que la obediencia, lejos de aminorar la dignidad de la persona humana, la lleva a una plena madurez, con la ampliada libertad de los hijos de Dios, agrega a los superiores: "Los superiores, por su parte, que han de dar cuenta a Dios de las almas que se les han confiado (cfr. Hebr. 13, 17), dóciles a la voluntad de Dios en el desempeño de su cargo, ejerzan su autoridad con espíritu de servicio a los hermanos, de suerte que manifiesten la caridad con que Dios los ama. Dirijan a sus súbditos como a hijos de Dios y con respeto a la persona humana, promoviendo su subordinación voluntaria. Por tanto, déjenles sobre todo la libertad debida en cuanto al sacramento de la penitencia y la dirección de conciencia. Hagan que los súbditos cooperen con obediencia activa y responsable en el cumplimiento del deber y en las empresas que se les confíen. Así, pues, los superiores han de escuchar gustosos a los súbditos y promover sus anhelos comunes para el bien del instituto y de la Iglesia, salva, con todo, su autoridad de determinar y ordenar lo que hay que hacer" ${ }^{69}$. Como puede apreciarse, la aplicación de lo expuesto se lleva a sus últimas consecuencias en la renovación de la vida religiosa.

En lo referente a autoridad y obediencia, topamos todavía con otra categoría de cristianos, en cierta medida subordinados, y son los seglares en lo pertinente al apostolado. $\mathrm{Y}$ en este punto se recuerda a los presbíteros: "Reconozcan y promuevan sinceramente los presbíteros la dignidad de los seglares y la suya propia y el papel que desempeñan los seglares en la misión de la Iglesia. Respeten a sí mismo cuidadosamente la justa libertad que todos tienen en la ciudad terrestre. Escuchen con gusto a los seglares, considerando fraternalmente sus deseos

\footnotetext{
66 Ibid. 9, BAC, 691.

67 Ibid. 12, BAC, 696; cfr. también 14, BAC. 698-699.

68 Decr. Sobre el ministerio y vid a de los presbíteros 15, BAC, 436-438. "

69 Decr. Perfectae caritatis = Sobre la adlecuada renovación de la vída religiosa 14, BAC, 49:2-493.
} 
y aceptando su experiencia y competencia en los diversos campos de la actividad humana; a fin de poder reconocer juntamente con ellos los signos de los tiempos... Encomienden también confiadamente a los seglares trabajos en servicio de la Iglesia, dejándolos libertad y radio de acción, invitándolos incluso oportunamente a que emprendan sus obras por propia iniciativa" 70 .

$\mathrm{Y}$ esto mismo quiere hacer en las misiones, donde los discípulos de Cristo "no buscan el progreso y la prosperidad meramente materiales de los hombres, sino que promueven su dignidad y unión interna, enseñando las verdades religiosas y morales, que Cristo esclareció con su luz, y con ello preparan gradualmente un acceso más amplio hacia Dios" 71. Para el logro de esta dignidad y de esa fraternidad mayor cooperará con todos, cristianos o no cristianos, dando de ese modo testimonio de auténtica búsqueda de elevación humana ${ }^{72}$.

$\mathrm{Si}$ de lo religioso pasamos a lo cultural, nos hallamos frente a las mismas conclusiones. El derecho a la educación brotaba de la dignidad de la persona humana y las consecuencias, que imponía ese hecho, son ampliamente deducidas. "Todos los hombres, de cualquier raza, condición y edad, en cuanto participantes de la dignidad de la persona, tienen el derecho inalienable a una educación, que responda al propio fin, al propio carácter, al diferente sexo, y que sea conforme a la cultura y a las tradiciones patrias, y al mismo tiempo, esté abierta a las relaciones fraternas con otros pueblos a fin de fomentar en la tierra la verdadera unidad y paz" ${ }^{73}$. Se ponen nuevamente a contribución aquí las Enc. Mater et Magistra y Pacem in terris, en las que se enumeran los derechos fundamentales del hombre y se los coloca en su verdadera luz. Y la formación cultural ha de impartirse siempre en función de la persona humana y para su servicio en los múltiples quehaceres que la vida le promete ${ }^{74}$.

En el orden social descubrimos el mismo resfeto a la dignidad, garantizado por el magisterio que en esta ocasión se declara con gallardía. La persona viene considerada en sus multiformes manifestaciones y la caridad, que fructifica en el respeto, se alarga y esclarece. Nadie queda excluído de ese respeto y a todos se impone la obligación de lo positivo y de lo negativo, del hacer y del evitar. En lo positivo tenemos esta declaración: "En nuestra época principalmente, urge la obligación de acercarnos a todos y de servirlos con eficacia cuando llegue el caso, ya se trate de ese anciano abandonado de todos, o de ese trabajador extranjero despreciado injustamente, o de ese desterrado, o de ese hijo ilegítimo que debe

70 Decr. Sobre el ministerio y vida de los presbitieros 9, BAC, 422-423.

71 Decr. Ad gentes 12, BAC, 585.

72 Decr. Unitatis redintelgratio = Sobre ell ecumenismo 12, BAC, 648. Puede verse esto mismo en repetidas ocasiones en el Decr. Ad gentes para las misiones, y en la Decl. Sobre las relaciones de la Iglesia con las religiones no cristianas. 73 Decl. Sobre la educación cristiana 1, BAC, 704; cfrr. también Const. past. Gaudium et spes 60, B:AC, 299-301.

74 Const. past. Gaudium et spies 56, BAC, 294; 61-62, BAC, 301-305. 
aguantar sin razón el pecado que él no cometió, o de ese hambriento que recrimina nuestra conciencia, recordando la palabra del Señor: cuantas veces bicisteis eso a uno de estos mis bermanos menores, a mi me lo bicisteis (Mt. 25, 40)".

Mientras que en lo negativo se pone a vergüenza pública esa falta de respeto a las personas que implican las cosas que cita, que harían enrojecer a un mundo como el nuestro que se precia de civilizado y de buscar una vida más humana: "No sólo esto. Cuanto atenta contra la vida - homicidios de cualquier clase, genocidios, aborto, eutanasia, y el mismo suicidio deliberado-; cuanto viola la integridad de la persona humana, como, por ejemplo, las mutilaciones, las torturas morales o físicas, los conatos sistemáticos para dominar la mente ajena; cuanto ofende a la dignidad humana, como son las condiciones infrahumanas de vida, las detenciones arbitrarias, las defortaciones, la esclavitud, la prostitución, la trata de blancas, y de jóvenes; o las condiciones laborales degradantes, que reducen al operario al rango de mero instrumento de lucro, sin respeto a la libertad y a la responsabilidad de la persona humana: todas estas prácticas y otras parecidas son en sí mismas infamantes, degradan la civilización humana, deshonran más a sus autores que a sus víctimas y son totalmente contrarios al honor debido al Creador" 75 .

Aquí se apelaba al mundo del trabajo y también en él la persona es esencial. El trabajador no puede convertirse en instrumento de la empresa, ya que el mismo trabajo humano es muy superior a los demás elementos de la vida económica. "Pues el trabajo humano, autónomo o dirigido, procede inmediatamente de la persona, la cual marca con su impronta la materia sobre que trabaja y la somete a su voluntad. Es para el trabajador y para su familia el medio ordinario de subsistencia; por él el hombre se relaciona con sus hermanos y les hace un servicio, puede practicar una verdadera caridad y cooperar al perfeccionamiento de la creación divina. No sólo esto. Estamos persuadidos de que con la oblación de su trabajo a Dios, los hombres se asocian a la obra redentora de Jesucristo, quien dio al trabajo una dignidad sobreeminente laborando con sus propias manos en Nazaret. De aquí se deriva para todo hombre el deber de trabajar, así como el derecho al trabajo". Pero este derecho postula la reverencia a la dignidad humana y por tanto no puede permitir que se trate al trabajador como un instrumento más de productividad, cosa que, por desgracia —afirma el Concilio- es demasiado frecuente hoy. "Los trabajadores deben tener, además, la posibilidad de desarrollar sus cualidades y su personalidad en el trabajo mismo" 76 .

Trabajo y economía están íntimamente relacionados y se implican mutuamente. Por eso "también en la vida económico-social deben respetarse y promoverse la dignidad de la persona humana, la vocación íntegra del hombre y el bien

75 Ibid. 27, BAC, 245-246.

76. Ibid. $67, \mathrm{BAC}, 312-313$. 
de la sociedad entera. Porque es el hombre el autor, el centro y el fin de toda vida económico-social" "77. Y por tanto el progreso y el desarrollo económico-social ha de estar controlado por el hombre, y no por unos pocos o por unos grupos económicamente poderosos en exceso, sino por el mayor número posible de hombres ${ }^{78}$. Porque "la finalidad fundamental de la producción no es el mero incremento de productos, ni el beneficio mayor, ni el poder, sino el servicio del hombre, del hombre integral, teniendo en cuenta sus necesidades materiales y sus aspiraciones intelectuales, morales, espirituales y religiosas; de todo hombre — decimos-, de todo grupo de hombres sin distinción de raza o de continente" 79.

Este mismo respeto a los derechos de la persona se palpa en lo político ${ }^{80}$, y en la promoción del bien comin 81 .

Colocando al hombre en su puesto en el mundo, la Iglesia toma conciencia de su dignidad y de sus valores y se ha trocado hoy más que nunca en defensora vigorosa de esos valores. Los ha ido desgranando en todos los órdenes y esos principios valen para todo problema que pueda plantearse luego. Por eso siendo tan interesante el tema y sabiendo que para lo cristiano es base y fundamento lo humano, ha repetido también la necesidad de una captación y de un cambio de mentalidad en este sentido, para una mayor comprensión de este margen, en algunos ambientes un poco olvidado, de la vida cuotidiana.

\section{FORMACIÓN HUMANA.}

Dado el convencimiento y la persuasión que encierran todos los documentos y las amonestaciones y las exhortaciones y los mandatos en ocasiones para los católicos, era lógico que se insistiera en una formación bumana a esos valores para situarlos en la mente y en el corazón de los hombres, y de modo especial de los cristianos. La Iglesia "promueve en todos los pueblos la perfección cabal de la persona humana, incluso para el bien de la sociedad terrestre y para configurar más humanamente la edificación del mundo" ${ }^{82}$. Y el hombre, como hemos ya señalado, no es sólo un espíritu, sino que tiene también un cuerpo con los derechos que éste puede hacer valer. Es lá perfección cabal de la persona bumana; no de una parte de ella, la que hay que formar y educar y prómover, como era la persona humana íntegra la que había que salvar. A este respecto, en el deber de enseñar

77 Ibid. $63, \mathrm{BAIC}, 306$.

Ibid. 65, BAC, 309 .

Ibid. 64, BAC, 308-309.

Ibid. 73, BAC, 322-323.

81 Decl. Dignitatis humamae 6, BAC',687; 9, BAC, 689, y repetidamente en la C'onst. past." Gaudium et spes.

82 Decl. Sobre la educación cristiana 3, BAC, 709. 
de los Obispos no solamente se alude a lo puramente espiritual o teológico, sino que se apela a que "muestren que las mismas cosas terrenas y las instituciones humanas, por la determinación de Dios Creador, se ordenan también a la salvación de los hombres.y, por consiguiente, pueden contribuir mucho a la edificación del Cuerpo de Cristo.

"Enseñen —continúa el Decreto-, por consiguiente, cuánto hay que apreciar la persona humana, con su libertad, y la misma vida del cuerpo, según la doctrina de la Iglesia; la familia y su unidad y estabilidad, la procreación y educación de los hijos; la sociedad civil con sus leyes y profesiones; el trabajo y el descanso, las artes y los inventos téonicos; la pobreza y la abundancia, y expongan, finalmente, las razones por las que hay que resolver los gravísimos problemas acerca de la posesión de los bienes materiales, de su incremento y recta distribución, acerca de la paz y de la guerra y de la vida hermanada de todos los pueblos" 83. La función providencial de lo humano en la historia de la salvación muestra su nueva faz y los Obispos deben promover esa perfección cabal de las personas, con el fin de que no sea manca y de que el reino de Cristo se inyecte en todas las estructuras personales y sociales. Mas como éste exige un sentido y una razón, de ahí que se imponga o al menos se aconseje al deber episcopal el enseñar todo esto con sus móviles.

La formación bumana integral ocupará todos los valores a que bemos becho referencia, juntamente con la concepción precedente del hombre 'y la sensibilización a los problemas angustiosos que lo conmueven. Era el verdadero espíritu de caridad traducido en la trivialidad de la vida ordinaria. $Y$ puesto que elegimos el orden religioso como el primero en la aplicación, citemos como punto de arranque la formación bumana de los seminaristas: "Obsérvense exactamente las normas de la educación cristiana y complétense convenientemente con los últimos hallazgos de la sana psicología y de la pedagogía. Por medio de una educación sabiamente ordenada hay que cultivar también en los alumnos la madurez humana, la cual se comprueba, sobre todo, en cierta estabilidad de ánimo, en la facultad de tomar decisiones ponderadas y en el recto modo de juzgar sobre los acontecimientos y los hombres. Esfuércense los alumnos en moderar bien su temperamento; edúquense en la reciedumbre de alma y aprendan a apreciar, en general, las virtudes que más se estiman entre los hombres y que recomiendan al ministro de Cristo, como son la sinceridad de alma, la preocupación constante de la justicia, la fidelidad en las promesas, la urbanidad en el obrar, la modestia unida a la caridad en el hablar" ${ }^{84}$. No se precisa explicación alguna. Está claro.

$Y$ era natural que si se recomienda una formación a la madurez y a esos valores, se exigirían también virtudes bumanas al presbítero, ayudas eficaces para

83 Decr. Sobre el ministerio pastoral de los obispos 12, BAC, 366.

84 Decr. Sobre la formación swaerdotal 11, BAC, 466. 
conseguir el conformarse al Pastor de los pastores, a Cristo. Hace referencia a las siguientes: "la bondad de corazón, la sinceridad, la fortaleza de alma y la constancia, la asidua preocupación de la justicia, la urbanidad y otras cualidades que recomienda el apóstol Pablo cuando escribe: Pensad en cuanto bay de verdadero, de puro, de justo, de santo, de amable, de laudable, de virtuoso, de digno de alaban$z a$ (Phil. 4, 8)" 85. Y un medio preciso del que extraerán un fruto precioso es el de la convivencia, por la "cual, siendo amigable y fraterna entre sí y con los demás hombres pueden aprender a cultivar los valores humanos y a apreciar los bienes creados como dones de Dios" ${ }^{86}$. Aquellos valores que analizamos entre los sociales ejercen un interés especial para el presbítero y por tanto a ellos también se formarán los seminaristas.

Estas virtudes y valores humanos se alegarán como fundamento a la reciedumbre de la fe, la esperanza y la caridad exigidos luego al misionero. Es el hombre quien ha de soportar el peso del día y del calor y es a través de muchos valores humanos cómo la gracia fecundará en el espíritu. Por eso el misionero "debe ser capaz de iniciativas, constante para continuar hasta el fin, perseverante en las dificultades, paciente y fuerte en sobrellevar la soledad, el cansancio y el trabajo infructuoso. Se presentará a los hombres con apertura de alma y grandeza de corazón; recibirá con gusto los cargos que se le confíen; se acomodará generosamente a las costumbres ajenas y a las mudables condiciones de los pueblos; ayudará a sus hermanos y a todos los que se dedican a la misma obra con-éspíritu de concordia y de caridad mutua, de suerte que, imitando juntamente con los fieles la comunidad apostólica, constituya un solo corazón y un alma sola (cfr. Act. $2,42 ; 4,32)$ " 87 . Espíritu de iniciativa, constancia, reciedumbre, paciencia, flexibilidad, diálogo, convivencia y comprensión: he ahí unas virtudes que deben adornar al heraldo del Evangelio, que revestirá luego -o mejor al mismo tiempoelevando aquéllas la fe, la esperanza y la caridad, como continúa ese párrafo del Decreto.

En la formación. de los seglares para el apostolado, luego de enumerar las virtudes espirituales y la espiritualidad que ha de acompañar su vida concreta y su profesión, se accede a lo social y humano. "Aprecien también como es debido la pericia profesional, el sentimientơ familiar y cívico y esas virtudes que exigen las costumbres sociales, como la honradez, el espíritu de justicia, la sinceridad, la delicadeza, la fortaleza de alma, sin las que no puede darse la verdadera vida cristiana" 88. Más tarde se estriba en el mismo argumento, como fundamento: "La formación para el apostolado supone una cierta formación humana, íntegra,

Decr. Sobre el ministierio y vidla de los pnesbiteros 3, BAC, 407.

Ibid. $17, \mathrm{BAC}, 441$.

Decr. Ad gentes 25, BAC, 607-608.

Decr. Sobre el apostolado de los seglares 4, BAC, 509. 
acomodada al ingenio y a las cualidades de cada uno. Porque el seglar conociendo bien el mundo contemporáneo, debe ser un miembro acomodado a la sociedad de su tiempo y a la cultura de condición" 89 . Y para ello necesita una formación doctrinal completa en todos los aspectos, teológica, ético-social, filosófica, sin despreciar ninguno de los sectores de la persona humana, sino cultivando y buscando siempre la unidad y la integridad de la persona y su armonía y equilibrio 90 .

La cultura ha de aspirar a una formación íntegra del hombre, aunque hoy más que nunca se ve dificultada la síntesis de los conocimientos. "Sin embargo queda en pie para cada hombre el deber de conservar la estructura de toda la persona humana, en la que destacan los valores de la inteligencia, voluntad, conciencia y fraternidad; todos los cuales se basan en Dios Creador y han sido saneados y elevados maravillosamente en Cristo" gp. La finalidad, empero, de la educación, a pesar de las varias dificultades que hoy surgen, se mantiene y esa finalidad se nos define en los siguientes términos, que son todo un programa, comprensivo de todos los elementos personales: "La verdadera educación se propone la formación de la persona humana en orden a su fin último y al bien de las sociedades, de las que el hombre es miembro y en cuyas responsabilidades tomará parte una vez llegado a la adolescencia.

"Hay que ayudar, pues, a los niños y a los adolescentes, teniendo en cuenta el progreso de la psicología, de la pedagogía y de la didáctica, para desarrollar armónicamente sus condiciones físicas, morales e intelectuales, a fin de que adquieran gradualmente el sentido más perfecto de la responsabilidal en el recto y laborioso desarrollo de la vida, y en la consecución de la verdadera libertad, superando los obstáculos con grandeza y constancia de alma. Hay que iniciarlos, conforme avanza su edad, en una positiva y prudente educación sexual. Hay que prepararlos además, para la participación en la vida social, de forma que, bien instruídos con los medios necesarios y oportunos, puedan participar activamente en los diversos grupos de la sociedad humana, estén dispuestos para el diálogo con los otros y presten su fructuosa colaboración gustosamente a la consecución del bien común" 92.

En breve y clara síntesis se nos han ofrecido los valores humanos a que la formación debe tender: responsabilidad, libertad, frutos de la dignidad hụmana y participación en la vida social, a través del diálogo y de la colaboración. Ia renovación de la sociedad comienza justamente en la formación y educación de los niños, los adolescentes y los jóvenes, y si se pide un cambio de mentalidad, las categorías es preciso cambiarlas en esas edades. La conclusión de este apartado

89 Ibid. 29, BAC, 541.

Ibid., BAIC, 542-543.

Const. past. Gaudium et spies 61, BAC, 301.

92 Decl. Sobre la educación cristiana 1, BAC, 704-705. 
no puede ser más lógica, como resumen de la nueva orientación más humana y más cristiana.

\section{HACIA UN NUEVO HUMANISMO.}

Una finalidad se ha dejado sentir en el mundo actual y ha esparcido su voz desde el Concilio. Crear una vida más bumana: he ahí una meta digna. $Y$ esa vida más humana se busca - los Decretos así lo dicen- a través de la cultura ${ }^{93}$, a través de lo político y de lo social ${ }^{94}$, por medio de las comunidades que tantean y coloquian por la paz ${ }^{95}$, a través de todos los medios de que se dispone en la actualidad. No había secretos: la religión católica busca y cuida una vida más humana. Y ésta pide fraternidad y trato con todos: "No podemos invocar a Dios, Padre de todos, si nos negamos a conducirnos fraternalmente con algunos hombres, creados a imagen de Dios. La relación del hombre para con Dios Padre y con los demás hombres, sus hermanos, están en tal forma unidas que, como dice la Escritura, el que no ama, no ba conocido a Dios (Io. 4,8)" 96. No haya distinción $\mathrm{ni}$ racismos. El amor allana todas las fronteras.

"Somos testigos de que nace un nuevo humanismo, en el que el hombre queda definido principalmente por su responsabilidad hacia sus hermanos y ante la historia" 97 . He aquí el nuevo humanismo de la responsabilidad y del sacrificio, el humanismo exigido por el amor evangélico. Y la explicación se hallaba en aquella frase de Pablo VI en la que se decía que "la antigua historia del samaritano ha sido el paradigma de la espiritualidad del Concilio". La visión optimista y providencialista que se había impuesto como lema pastoral ha fructificado plenamente en una aceptación de valores que se han dignificado y se han situado en su justo lugar. La religión se ha puesto al servicio del hombre. Pone en relación al hombre con Dios y da a la vida humana su significado auténtico y su sentido, porque para conocer al hombre integral es necesario conocer a Dios. Las palabras de Pablo VI pueden ser broche de oro de este capítulo y ellas nos descubren el profundo alcance del optimismo en la persona humana. He aquí el nuevo humanismo dibujado en cristianismo y convertido: "Y si recordamos — decía en el Discurso del 7 de diciembre en la Sesión pública con que se clausuraba el Concilio-, venerables hermanos e hijos todos aquí presentes, cómo en el rostro de cada hombre, especialmente si se ha hecho transparente por sus lágrimas y por sus

93 Const. past. Gaudium et spes 57, BAC, 294-296.

94 Ibid. 74, BA.C, 323-324.

95 Ibid. 77, BAC, 331-332.

96 Decl. Sobre las relaciones de la Iglesia con las religiones no cristianas 5, BAC, 728-729.

97 Const. past. Gaudium et spes 55, BAC, 292. 
dolores, podemos y debemos reconocer el rostro de Cristo (cfr. Mt. 25, 40), el Hijo del hombre, y si en el rostro de Cristo podemos y debemos, además, reconocer el rostro del Padre celestial: Quien me ve a mí-dijo Jesús-ve también al Padre (Io. 14, 9), nuestro humanismo se hace cristianismo, nuestro cristianismo se hace teocéntrico, tanto que podemos afirmar también que para conocer a Dios es necesario conocer al hombre.

"¿Estaría destinado entonces este Concilio, que ha dedicado al hombre principalmente su estudiosa atención, a proponer de nuevo al mundo moderno la escala de las liberadoras y consoladoras ascensiones? ¿No sería, en definitiva, un simple, nuevo y solemne enseñar a amar al hombre para amar a Dios? Amar al hombre - decimos- no como instrumento, sino como primer término hacia el supremo término trascendente, principio y razón de todo amor, y entonces este Concilio entero se reduce a su definitivo significado religioso, no siendo otra cosa que una potente y amistosa invitación a la humanidad de hoy a encontrar de nuevo, por la vía del amor fraterno, a aquel Dios "de quien alejarse es caer, a quien dirigirse es levantarse, en quien permanecer es estar firmes, a quien volver es renacer, en

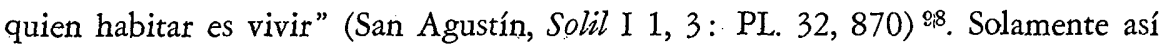
podía decirse el Concilio un solemne acto de amor a la humanidad y podía repetir Pablo VI con grito de alegría que "hemos aprendido a amar más y a servir mejor a la humanidad" 99 , aprendido a "amar al hombre de hoy tal cual es" 100 . Una caridad que se actualiza, es decir, se hace presente hoy.

P. José Morán, O. S. A.

98 Pablo VI, Al. 7-XII-1965, BAC, 819.

99 Ibid.

100 ID., Al. 10-IX-1965, BAC, 802. 